\title{
Recurrent apnoeic attacks as a manifestation of epilepsy
}

\author{
T. J. WALLS \\ B.Med.Sci., M.B., M.R.C.P. \\ P. K. NeWMAN \\ M.B., M.R.C.P. \\ W. J. K. Cumming \\ B.Sc., M.D., M.R.C.P.I. \\ Regional Neurological Centre, Newcastle General Hospital, Westgate Road, Newcastle upon Tyne
}

\begin{abstract}
Summary
A case is reported of epilepsy associated with recurrent apnoeic attacks. These episodes were modified by treatment and by the passage of time. Central respiratory arrest may be an unrecognized feature of epilepsy in other patients.
\end{abstract}

\section{Introduction}

Hughlings Jackson observed in 1899 that asphyxia may be a feature of uncinate fits, suggesting that the arrest of respiration was 'by great cortical inhibition of the respiratory (medulla) centre'. He described the case of a 52-year-old male with epilepsy in whom attacks of impaired consciousness and lip smacking were followed by cyanosis and dropping of the arms 'soft, not stiff', implying that the disturbance of respiration was central and not due to chest spasm. The present communication reports a patient with epilepsy in whom seizures were associated with repeated episodes of respiratory arrest.

\section{Case report}

A 25-year-old female presented in March 1979, following an episode of respiratory arrest. Seven years previously she had had a series of attacks of loss of consciousness with urinary incontinence which remitted after one year. The electroencephalograph (EEG) was then normal. In September 1978, shortly after termination of a pregnancy, she was found unconscious, breathing irregularly and with an apparent left hemiparesis. She recovered several hours later but a number of further episodes of unconsciousness and disorganized respiration occurred the next day. Investigations including computerized tomography (CT) scan and lumbar puncture were normal, and no further action was taken.

Six months later the patient was undergoing outpatient traction for sciatica, when she suffered respiratory arrest and required endotracheal intubation and assisted ventilation. She was transferred to the Regional Neurological Centre where during the next 6-8 weeks she had more than 30 such attacks. Each began with fluttering of the eyelids and twitching of the jaw followed, after 5-6 breaths of diminishing volume, by cessation of respiration. Consciousness was lost at this time, the patient became deeply cyanosed and on each occasion respiratory assistance with oro-pharyngeal airway and Ambu bag was necessary. Oculocephalic, corneal and gag reflexes were absent and the pupils dilated during the period of apnoea. Between 5-30 min after the onset of apnoea, a brief period of ataxic breathing preceded return of normal respiration, and consciousness was regained, the patient remaining confused and drowsy for a variable period, on some occasions for the rest of the day. In addition to the above attacks, she had a large number of more prolonged periods of unconsciousness, with diminution of rate and amplitude of respiration but no observed apnoea. During these episodes tachycardia, sweating, hypertension, pyrexia and pupillary dilatation were noted, neck stiffness was often present, and on one occasion marked opisthotonus occurred.

Normal investigations included haematological, biochemical and serological profiles, interictal acidbase balance, CT scan, vertebral angiography, spinal fluid analysis, brain stem-evoked potentials, electrocardiograph and interictal EEG. During a prolonged EEG recording combined with respiratory monitoring by thoracic strain gauge, several periods of disordered respiration were associated with generalized slowing of the EEG. An EEG with thiopentone sedation was unremarkable, but during a sphenoidal recording the response to i.v. bemegride demonstrated bitemporal focal sharp waves in addition to generalized spike and wave activity. Continuous EEG monitoring for 3 
days and nights gave no further information, no apnoeic attacks occurring during this period. The EEG 4 months later showed a general deterioration with localized slow activity and focal sharp waves originating from the right anterior head region, but a further prolonged recording was again unhelpful. Psychometric assessment using the Wechsler Adult Intelligence Scale gave a verbal IQ of 83, performance IQ of 91 and subsequently showed no suggeston of any progressive deterioration.

During a period of 4 months the attacks became modified and more typically epileptic, often with focal motor features on one or other side and with shallow breathing but without apnoea. Methylphenidate increased their frequency, carbamazepine was without effect, and optimum suppression was obtained with phenytoin, clonazepam and sodium valproate in combination. Clomipramine was subsequently added because of concurrent depression. Twelve months later the patient was no longer subject to apnoeic episodes, but had a minor seizure associated with shallow breathing about once every 3 weeks, usually occurring at night. Two years later, she is free of apnoeic attacks but seizure control has again become difficult. She has had an uneventful pregnancy and been delivered of a normal child.

\section{Discussion}

This patient presented with episodes of sudden loss of consciousness and apnoea. Intermittent respiratory arrest during sleep is characteristic of sleep apnoea (Guilleminault, van den Hoed and Mitler, 1978), but this patient had apnoeic attacks associated with a state of unresponsiveness that was clearly different from normal sleep. The attacks were of rapid onset, characterized by sudden interruption of normal behaviour and gradual resolution into a state of drowsiness. There were few other features of epilepsy initially but, as time passed, the attacks became more typically epileptiform and some EEG abnormalities appeared. The autonomic disturbances noted during this patient's attacks would be compatible with a seizure discharge in the limbic system.

Epilepsy may interfere with respiration in a number of ways. The chaotic respiration of the clonic phase and the spasmodic chest fixation of the tonic phase of a grand mal convulsion are familiar and a number of other breathing disorders have also been described as manifestations of seizure activity (Lennox, 1960). Stimulation of the uncus in experimental animals was shown many years ago to produce apnoea (Spencer, 1894) and in man, stimulation of limbic and temporal cortical structures may produce respiratory arrest (Kaada and Jasper, 1952).
A search of the literature reveals a report of a case of prolonged apnoeic episodes in an adult wift temporal lobe epilepsy (Nelson and Ray, 1968) an $\vec{A}$ of a child aged 3 years with apnoeic seizures astsociated with slowing of the background EEG recofed and responsive to atropine (Hooshmand, 1972 EEG monitoring of premature infants with seve recurrent apnoeic episodes has revealed that some of these episodes are associated with high voltage frontal rhythmical discharges and opisthoton $\vec{\Theta}$ (Deuel, 1973) and recently a patient with progressive dialysis encephalopathy has been describeg who had recurrent episodes of apnoea associates with high voltage slowing of the EEG (Garcif Bunuel, Elliott and Blank, 1980).

The present authors have been unable to find reference in the literature to any patient suffering the number, severity and duration of apnoeic attacks that they describe, and of particular interest is the gradual modification of these attacks to moxe familiar seizure patterns. This case report leađs further support to the concept of seizure inhibition of respiratory control centres and consequet apnoea, as suggested by Hughlings Jackson (1899) Although death during an epileptic seizure is usualfy ascribed to mechanical factors interfering with ventilation, it is possible that direct epilept tid respiratory arrest may be responsible in some cages?

\section{Acknowledgments}

The authors thank Dr Peter Hudgson for permission report this case and are grateful to Dr David Barwick, Migs Pat Longley and colleagues for the EEG studies.

\section{References}

Deuel, R.K. (1973) Polygraphic monitoring of apnoerc spells. Archives of Neurology, 28, 71.

Garcia-Bunuel, L., Elliott, D.C. \& Blank, N.K. (1980) Apnoeic spells in progressive dialysis encephalopathy. Archives of Neurology, 37, 594.

Guilleminault, C., van den Hoed, J. \& Mitler, M.M: (1978) Clinical overview of the sleep apnoea syndromes. In: Sleep Apnoea Syndromes (Ed by Guilleminault, C. Dement, W.C.), p. 2. Allan R. Liss Corporation, N\& York.

Hooshmand, H. (1972) Apnoeic seizures treated with atropine. Neurology, 22, 1217.

JACKSON, J.H. (1899) On asphyxia in slight epileptic pafi oxysms. Lancet, 79.

KAADA, B.R. \& JASPER, H. (1952) Respiratory responses to stimulation of temporal pole, insula and limbic gyri $\Re$ man. Archives of Neurology and Psychiatry, 68, 609.

Lennox, W.G. (1960) Epilepsy and Related Disorders, 336. J. and A. Churchill, London.

Nelson, D.A. \& RAY, C.D. (1968) Respiratory arrest froi seizure discharges in limbic system. Archives of Neurologo, $19,199$.

SPENCER, W.G. (1894) The effect produced upon respiration by faradic excitation of the cerebrum in the monkey, dog cat and rabbit. Transactions of the Royal Society, 185, 60\% 